Original Article

\title{
Effects of shoulder stabilization exercise on pain and function in patients with neck pain
}

\author{
Youna Lee, PT, MSc ${ }^{1)}$, Mary Myong Sook Shin, MA²), Wanhee Lee, PT, PhD* \\ 1) Department of Physical Therapy, Sahmyook University: 26-21 Gongneung 2-dong, Nowon-gu, Seoul \\ 139-742, Republic of Korea \\ 2) Department of English, Sahmyook University, Republic of Korea
}

\begin{abstract}
Purpose] The objective of this study was to investigate the effects of shoulder stability exercise on pain and function in neck pain patients. [Subjects] The study design consisted of a shoulder stability exercise group and a control group. [Methods] The effects of the therapies were evaluated using a visual analog scale of pain, a pressure pain threshold, neck disability index, cervical range of motion, and a closed kinetic chain test. Each group received treatment five times per week for 4 weeks. [Results] Pain levels showed no significant differences between groups, while pain threshold in all muscles, showed significant increases for both control groups. Neck disability significantly decreased for both groups and the differences between the groups were statistically significant. Ranges of motion and limb stability were measured before and after the exercise period. Flexion, extension, and right rotation were not significantly different between groups. The results showed no significant differences in shoulder stability between the groups. [Conclusion] The use of this exercise should have pronounced effects on pain reduction and functional improvement and should also improve the quality of life in patients with neck pain.

Key words: Neck pain, Shoulder stabilization training, Neck stabilization training
\end{abstract}

(This article was submitted Jun. 11, 2015, and was accepted Aug. 30, 2015)

\section{INTRODUCTION}

Neck pain may originate from muscle, ligament, bursa, disc, neuromuscular junction, or from other problems that result in pain. Neck pain can develop in any individual, generally first presenting as a headache, but also sometimes as shoulder pain. It is a cumulative condition occurring because of musculoskeletal damage to the cervical muscles, joints, nerves and is often caused by stressful work related conditions and long working hours. Changes in working conditions in recent years have led to an increase in the number of patients being referred to the hospital for neck pain ${ }^{1)}$. When applying the scapula calibration strategy for patients with neck pain, improving the position of the scapula and trapezius creates an activity ratio of the upper parts that is close to the ratio of normal subjects ${ }^{2}$. Modifying the position of the scapula in patients with neck pain passively reduces pain levels. Additionally, the improvement range of motion and rotation of the neck and the proprioceptive have been reported to improve the position in relation to the position of the shoulder ${ }^{3}$. Although clear evidence exists for the efficacy of stabilization exercises in reducing neck pain, clear evidence for the other effects shown by several previous

*Corresponding author. Wanhee Lee (E-mail: whlee@syu. ac.kr)

(C2015 The Society of Physical Therapy Science. Published by IPEC Inc. This is an open-access article distributed under the terms of the Creative Commons Attribution Non-Commercial No Derivatives (by-ncnd) License $<$ http://creativecommons.org/licenses/by-nc-nd/3.0/> . studies is lacking ${ }^{4)}$.

In addition, results from previous studies remain controversial because most of the studies on the effects of shoulder stabilization exercises for reducing neck pain are crosssectional studies with no control group for comparison ${ }^{5)}$. For this reason, exercise treatments for neck pain patients tend to be based on the subjective judgment of the therapist, rather than on scientific evidence ${ }^{6}$. This study examined, it was necessary to consider the impact of the neck muscles around the scapula that can contribute to neck pain, the control of pain, the function of the neck, and whether shoulder stabilization exercises to strengthen the large muscles of the shoulder have any effect on the symptoms of neck pain. The effects of the addition of shoulder exercises to standard neck exercises were also examined in order to present a more effective rehabilitation method for the treatment of neck pain ${ }^{5)}$.

\section{SUBJECTS AND METHODS}

This study involved 30 patients between 20 and 60 years old who were diagnosed with neck pain by rehabilitation specialists at Hospital, Dae-Jeon. Patient inclusion criteria was a new diagnosis with complaints of neck pain of 3-7 on a visual analog scale (VAS), a neck disability index (NDI) of 15 points or more, and the ability to clearly hear and understand the exercises. Subjects were excluded if they had neurological symptoms due to problems with their cervical vertebrae, pain caused by vascular problems, severe orthopedic problems in the shoulder, other medical conditions, or if they were involved in another experiment for the duration of the study. A number of measurements were taken before the 
experiment began. The pressure pain threshold (PPT) was measured using the VAS and the pressure that reproduced that same level of pain in the neck was quantified. Function was measured using the cervical NDI and cervical range of motion (CROM) was determined using a cervical tilt sensor to directly record the range of motion ${ }^{7}$. Upper limb stability was measured using a closed kinetic chain test (CKCT) to test the stability of the shoulder ${ }^{8}$. The subjects were randomized into either the shoulder stabilization exercise group (SSEG) or the control group, with 15 people in each. At the end of the experiment, the SSEG included 14 people, as one person dropped out due to poor physical condition, and the control group included 12 people, with three people being excluded because of low participation rates. Prior to the subject's participation, all procedures were explained, and each subject provided his or her written informed consent to participate. This study was approved by the ethics committees of the Sahm-Yook University institutions. The shoulder stabilization exercise and the control groups both received conservative physical therapy, involving a 10-minute hot pack application, 10-minute electrical treatment, 3-minute ultrasound treatment, and 15-minute neck stability exercise rehimen, for a total of up to 40 minutes of treatment ${ }^{9}$. The SSEG received 20-minutes of shoulder stabilization exercises in addition to the 40-minute conservative physical therapy, for a total of up to 60 minutes of treatment. The exercise sessions were conducted five times per week, for 4 weeks ${ }^{10)}$. The SSEG and the control group all received the same number of sessions in a similar environment. All statistical analyses in this study were performed using the SPSS ver. 21.0 statistical software was used for all analyses. Results were calculated using the mean and standard deviation. The Kolmogorov-Smirnov test was used to determine the normality of the general characteristics and the parameters of the test subjects' homogeneity were tested by using an independent samples t-test and $\chi^{2}$ test. Changes in the dependent variable between the pre-test and post-test values were analyzed using a paired t-test. In order to compare the group effects, the independent samples t-test was used. The level of significance for all results was set at $\mathrm{p}$-value $<0.05$.

\section{RESULTS}

The subjects' general characteristics are presented in Table 1. No significant differences in general characteristics were observed between the SSEG and the control group (age: 67.14 and 60.41 years; height: 166.35 and $162.75 \mathrm{~cm}$; weight: 48.21 and $43.50 \mathrm{~kg}$; respectively). Differences in pre- and post-test values within groups and between groups are summarized in Table 2-1, Table 2-2. First, the PPT in both groups were significantly reduced in the upper trapezius, levator scapulae and splenius capitis, after exercise. Second, the NDI values were significantly lower in the SSEG compared to the control group and CROM, measured by right lateral flexion, left lateral flexion, and left rotation, was significantly higher in the SSEG than in the control group. Flexion, extension, and right rotation also increased to a greater degree in the SSEG than in the control group. Third, there were no significant differences in upper limb stability between the control group and SSEG $(p<0.05)$, but
Table 1. Characteristics of study participants

\begin{tabular}{lcc}
\hline Parameters & $\begin{array}{c}\text { SSEG } \\
(\mathrm{n}=14)\end{array}$ & $\begin{array}{c}\text { Control group } \\
(\mathrm{n}=12)\end{array}$ \\
\hline Age (years) & 67.1 & 60.4 \\
Height $(\mathrm{cm})$ & 166.3 & 162.7 \\
Weight $(\mathrm{kg})$ & 48.2 & 43.5 \\
\hline
\end{tabular}

Values are mean \pm standard deviation (SD).

SSEG: Shoulder stabilization exercise group

there was a significant difference between the control group and the SSEG $(\mathrm{p}<0.05)$.

\section{DISCUSSION}

Neck pain patients with more severe levels of upper limb dysfunction show a strong positive correlation with increased levels of neck pain. In a study in the United Kingdom of 151 patients with non-specific neck pain, neck pain and upper limb dysfunction showed a high positive correlation, with a correlation coefficient of 0.799 between the two variables ${ }^{12}$ ). There are a number of explanations for the correlation between neck pain, upper limb dysfunction, and reduced upper extremity strength. The first is the structural connectivity of the cervical spine and shoulders. The bones and muscles of the cervical spine and the shoulders are connected to each other mechanically, thus a continuously applied mechanical load on the shoulders directly increases the load on the cervical region, which may cause joint and ligament pain. This can be seen in certain occupational groups who use their shoulders more often than most workers. The second explanation is damage to peripheral nerves. The brachial nerves are linked structures that pass from the cervical spine to the shoulders. If shoulder movements result in cervical tissue elongation and sliding, this may cause symptoms typically seen in neck pain suffers. Sustained and repetitive movements of the shoulder and elongation of the nerves ${ }^{11)}$ may cause damage to the fine neural tissue leading to it becoming brittle and causing neck pain. In addition, movement of the shoulder may be limited because it induces neck pain in patients. The last explanation is the physical deterioration associated with neck pain. Neck pain leads to a rediction in the levels of activities that require the use of the neck and shoulder. This can lead to physical deterioration through a decrease in muscle strength, cardiovascular endurance, and ability $^{13)}$. In this study ${ }^{13)}$, the neck disability index rates patients' ability to eat, to do housework, and to carry heavy objects. Another study found that, when evaluating the performance of activities of daily living in patients with more severe neck pain it was found that they had more difficulty in performing the activities mentioned in the survey ${ }^{14)}$. In other studies, on the treatment and management of patients with severe neck pain, the effects of shoulder calibration and other current treatment approaches, have already been presented. This comprehensive foundation can be seen as an opportunity to examine the effects of these different approaches ${ }^{15}$. Research has shown that the active range of cervical rotation increases significantly when the shoulder of a healthy young adult is supported by placing the scapula in 
Table 2-1. Comparison of pain, function and shoulder stability within groups and between groups

\begin{tabular}{|c|c|c|c|c|c|c|}
\hline \multirow{3}{*}{ Parameters } & \multicolumn{4}{|c|}{ Values } & \multicolumn{2}{|c|}{ Different in Values } \\
\hline & \multicolumn{2}{|c|}{ SSEG $(n=14)$} & \multicolumn{2}{|c|}{ Control (n=12) } & \multirow{2}{*}{$\begin{array}{c}\text { SSEG }(n=14) \\
\text { Post-pre }\end{array}$} & \multirow{2}{*}{$\begin{array}{c}\text { Control }(\mathrm{n}=12) \\
\text { Post-pre }\end{array}$} \\
\hline & Pre & Post & Pre & Post & & \\
\hline VAS (score) & $5.21(1.05)$ & $2.42(1.39)$ & $4.75(1.05)$ & $3.75(3.07)$ & $2.78(1.25)$ & $1.00(3.27)$ \\
\hline \multicolumn{7}{|l|}{ PPT $\left(\mathrm{lb} / \mathrm{cm}^{2}\right)$} \\
\hline \multicolumn{7}{|l|}{ Right } \\
\hline upper trapezius & $8.89(2.20)$ & $12.92(1.97)$ & $10.58(2.43)$ & $10.66(3.05)$ & $4.35(2.30)$ & $0.08(1.57)$ \\
\hline levator scapular & $8.85(2.61)$ & $12.21(2.42)$ & $9.72(2.38)$ & $10.33(2.53)$ & $3.35(1.65)$ & $0.54(1.52)$ \\
\hline splenius capitis & $3.57(3.22)$ & $7.64(1.33)$ & $4.95(3.91)$ & $5.50(3.50)$ & $4.07(2.52)$ & $1.45(5.44)$ \\
\hline \multicolumn{7}{|l|}{ Left } \\
\hline upper trapezius & $8.35(2.21)$ & $11.92(2.26)$ & $9.12(2.23)$ & $10.33(2.53)$ & $3.57(2.28)$ & $1.20(0.27)$ \\
\hline levator scapular & $9.21(1.63)$ & $12.07(2.30)$ & $10.50(2.27)$ & $11.58(2.35)$ & $2.86(1.73)$ & $1.08(0.79)$ \\
\hline splenius capitis & $3.00(3.11)$ & $6.92(0.99)$ & $4.75(2.92)$ & $6.33(2.22)$ & $3.92(0.63)$ & $1.58(2.23)$ \\
\hline
\end{tabular}

Values are mean \pm standard deviation $(\mathrm{SD}),{ }^{*} \mathrm{p}<0.05$

VAS: visual analog scale ; PPT: pressure pain threshold; SSEG: shoulder stabilization exercise group

Table 2-2. Comparison of pain, function and shoulder stability within groups and between groups

\begin{tabular}{|c|c|c|c|c|c|c|}
\hline \multirow{3}{*}{ Parameters } & \multicolumn{4}{|c|}{ Values } & \multicolumn{2}{|c|}{ Different in Values } \\
\hline & \multicolumn{2}{|c|}{ SSEG $(n=14)$} & \multicolumn{2}{|c|}{ Control $(n=12)$} & \multirow{2}{*}{$\begin{array}{c}\text { SSEG }(n=14) \\
\text { Post-pre }\end{array}$} & \multirow{2}{*}{$\begin{array}{c}\text { Control }(\mathrm{n}=12) \\
\text { Post-pre }\end{array}$} \\
\hline & Pre & Post & Pre & Post & & \\
\hline NDI (score) & $21.42(4.61)$ & $12.58(4.53)$ & $22.58(6.00)$ & $17.66(6.62)$ & $8.57(3.73)$ & $4.91(4.58)$ \\
\hline \multicolumn{7}{|l|}{ CROM (Degree) } \\
\hline Flexion & $32.21(7.36)$ & $38.92(4.26)$ & $32.91(2.23)$ & $37.08(5.83)$ & $6.71(4.49)$ & $4.16(5.18)$ \\
\hline Extension & $36.42(8.71)$ & $40.07(5.90)$ & $38.75(12.75)$ & $41.08(8.55)$ & $3.64(4.51)$ & $2.33(5.74)$ \\
\hline Right side banding & $26.14(6.57)$ & $34.85(3.57)$ & $30.25(8.86)$ & $33.33(7.83)$ & $8.71(5.31)$ & $3.08(3.50)$ \\
\hline Left side banding & $29.14(5.60)$ & $34.35(6.05)$ & $33.00(9.95)$ & $35.25(8.12)$ & $5.21(0.89)$ & $2.25(2.79)$ \\
\hline Right rotation & $32.78(9.97)$ & $38.00(6.93)$ & $31.33(5.83)$ & $35.16(5.58)$ & $5.21(4.66)$ & $3.83(1.99)$ \\
\hline Left rotation & $34.21(8.44)$ & $38.42(5.66)$ & $37.83(8.37)$ & $39.00(6.68)$ & $4.21(4.00)$ & $1.16(3.32)$ \\
\hline CKCT (Count) & $4.14(0.41)^{*}$ & $6.35(1.27)$ & $3.91(0.66)$ & $5.58(0.66)$ & $2.21(1.10)$ & $1.66(0.77)$ \\
\hline
\end{tabular}

Values are mean \pm standard deviation (SD)

NDI: neck disability index; CROM: cervical range of motion; CKCT: closed kinetic chain test; SSEG: shoulder stabilization exercise group

the neutral position ${ }^{15)}$. This maneuver can also reduce symptoms of neck pain ${ }^{16)}$. Another study, examining cervicogenic headaches, compared the activity of the middle trapezius, lower trapezius, and serratus anterior when $30^{\circ}, 60^{\circ}, 90^{\circ}$, and $120^{\circ}$ of flexion were applied with the shoulder in a flexion, extension position ${ }^{17}$. Interventional approaches aimed at reducing uneven alignment, including repositioning of the scapula, have shown of a significantly decreased NDI score after 3 months, and a significantly increased $\mathrm{CROM}^{18)}$. It has been reported that cervical rotation increases with the shoulder abduction angle ${ }^{19)}$. This, in relation to the present study, can be best explained by the increased stabilization of that occurs during cervical rotation. In a study on healthy young adults, it was shown that, by supporting the upper limbs the active cervical rotation range was significantly increased when release the scapula was released to the neutral position. Therefore, when a neck pain patient raise their scapula, thereby increasing stability and supporting the weight of the upper limb, this rotation relieves the symptoms of cervical neck pain, indicating that the cause of the neck pain is through an injury affecting the scapular muscles. Comparing these results to those of the study, the previous results showed that there were no significant differences between groups in the stability of the upper limb, whereas in the current study, there was a significant difference between the SSEG and the control group. The current study shows that the occurs due to the manipulation of the scapula performed in the shoulder stabilization exercise and massage groups, compared to upper trapezius elongation per during shoulder stabilization exercise, provides greater relief to neck pain patients. This conclusion is supported by a study that shows a link between the cervical and scapular muscles ${ }^{20)}$. Previous studies have reported increased levels of stability in groups undergoing stretching exercises and massage, but these differences were not significantly different ${ }^{20)}$.

\section{REFERENCES}

1) Hwangbo PN, Hwangbo G, Park J, et al.: The effect of thoracic joint mobilization and self-stretching exercise on pulmonary functions of patients 
with chronic neck pain. J Phys Ther Sci, 2014, 26: 1783-1786. [Medline] [CrossRef]

2) Wegner S, Jull G, O’Leary S, et al.: The effect of a scapular postural correction strategy on trapezius activity in patients with neck pain. Man Ther, 2010, 15: 562-566. [Medline] [CrossRef]

3) Ha-yeon K, Suhn-yeop K: Effect of scapular stabilization exercise on patients with neck pain classified according to passive scapular elevation test Phys Ther Kor, 2012. 19.

4) $\mathrm{Ha} \mathrm{TH}$, Seo HS, Choo WJ, et al.: The effect of metabolic syndrome on myocardial contractile reserve during exercise in non-diabetic hypertensive subjects. J Cardiovasc Ultrasound, 2011, 19: 176-182. [Medline] [CrossRef]

5) Jeong JH, Hee KH: Effect comb exercise program patients chronic neck pain. 2011, 19: 176-182

6) Sarig-Bahat H, Weiss PL, Laufer Y: Neck pain assessment in a virtual environment. Spine, 2010, 35: E105-E112. [Medline] [CrossRef]

7) Lluch E, Arguisuelas MD, Coloma PS, et al.: Effects of deep cervical flexor training on pressure pain thresholds over myofascial trigger points in patients with chronic neck pain. J Manipulative Physiol Ther, 2013, 36 604-611. [Medline] [CrossRef]

8) Khademi Kalantari K, Berenji Ardestani S: The effect of base of support stability on shoulder muscle activity during closed kinematic chain exercises. J Bodyw Mov Ther, 2014, 18: 233-238. [Medline] [CrossRef]

9) Lee, G.-C.L.a.D.-Y: The effects of deep neck flexor exercise on pain and neck disability index of the patients with chronic neck pain. The Korea Academia Inderstrial Cooperation society, 2010, 26: 895-897.

10) da Costa DR, de Lima Ferreira AP, Pereira TA, et al.: Neck disability is associated with masticatory myofascial pain and regional muscle sensitivity. Arch Oral Biol, 2015, 60: 745-752. [Medline] [CrossRef]

11) McLean SM, May S, Klaber-Moffett J, et al.: Risk factors for the onset of non-specific neck pain: a systematic review. J Epidemiol Community
Health, 2010, 64: 565-572. [Medline] [CrossRef]

12) Van Damme S, Van Hulle L, Danneels L, et al.: The effect of chronic low back pain on tactile suppression during back movements. Hum Mov Sci, 2014, 37: 87-100. [Medline] [CrossRef]

13) Jin-Gang H: Effects of neck stabilization exercise to the patients with chronic neck pain. Korea Sport Res, 2006, 16: 488-492.

14) Van Dillen LR, McDonnell MK, Susco TM, et al.: The immediate effect of passive scapular elevation on symptoms with active neck rotation in patients with neck pain. Clin J Pain, 2007, 23: 641-647. [Medline] [CrossRef]

15) Andrade GT, Azevedo DC, De Assis Lorentz I, et al.: Influence of scapular position on cervical rotation range of motion. J Orthop Sports Phys Ther, 2008, 38: 668-673. [Medline] [CrossRef]

16) Weon JH, Oh JS, Cynn HS, et al.: Influence of forward head posture on scapular upward rotators during isometric shoulder flexion. J Bodyw Mov Ther, 2010, 14: 367-374. [Medline] [CrossRef]

17) Takasaki H, Hall T, Kaneko S, et al.: Cervical segmental motion induced by shoulder abduction assessed by magnetic resonance imaging. Spine, 2009, 34: E122-E126. [Medline] [CrossRef]

18) McDonnell MK, Sahrmann SA, Van Dillen L: A specific exercise program and modification of postural alignment for treatment of cervicogenic headache: a case report. J Orthop Sports Phys Ther, 2005, 35: 3-15. [Medline] [CrossRef]

19) Gong W: Impact of longus colli muscle massage on the strength and endurance of the deep neck flexor muscle of adults. J Phys Ther Sci, 2013, 25: 591-593. [Medline] [CrossRef]

20) Chan YC, Wang TJ, Chang CC, et al.: Short-term effects of self-massage combined with home exercise on pain, daily activity, and autonomic function in patients with myofascial pain dysfunction syndrome. J Phys Ther Sci, 2015, 27: 217-221. [Medline] [CrossRef] 